\title{
Object-Field: An Adaptive Interplay Between Autonomy and Contingency
}

\author{
SAMUEL BERNIER-LAVIGNE
}

Laval University

This paper focus on the relation between autonomy in the formal design of the architecture (the deductive) and the unpredictability associated with digital simulations (the inductive). Thus, we will take an analytical look at the evolution of the digital avant-garde in recent years, by studying the correlation between two fundamental entities: the object and the field.

\section{INTRODUCTION}

After a few decades of experimentation with digital tools, should we still raise the question of human control over the machine, in order to clarify which part of the project results from the architect's intuition as opposed to what is determined by the computer? While it is easy to identify the starting point of this discussion with cybernetics, the science of control introduced by Norbert Wiener, it is more complex to follow its recent ramifications. ${ }^{1}$

For observers outside the hermetic circle of digital architecture, this can represent a complete impasse. However, for digital designers, the situation is quite different. Throughout the composition of formal and algorithmic models, this dichotomy resurfaces at each step in the conceptual evolution of the project. Should we promote the intuition of the designer in the formal definition or rely on the unpredictability of generative processes?

To understand what is at stake, we intend to analyze the repercussions of such an issue on the progress of digital architecture, by studying the correlation between two fundamental entities: the object and the field. Following a chronological approach, we will first observe how the field will materialize flows of data into architectural masses, where the emergence of a singularity is dictated by local relationships.

Then, a first interaction between these two elements will lead to the field of objects, while the architectural geometries will vary according to the contextual data. In reaction to this will come the architectural object, as an autonomous entity created from scratch by the architect. Finally, we will get to the core of the argument with the concept of the object-field, which proposes a reconciliation, as an adaptive interplay, between autonomy in architectural design and the contingency of digital simulation. This evolutionary sequence will allow us to go beyond both the field and the object, by merging them their potentials. Thus, a new chapter will add on the discussion that began in the 1990s.

\section{FIELD}

Since their discovery by Michael Faraday during his work on electromagnetism, force fields have explicitly shown that: "space is not an inert environment, but a field of energy, inhabited by an infinity of lines of force." 2 The spatial location of an object, and therefore its position in the force field immediately determine its relationship with the energy present. A few centuries later, an element of Faraday's research will be integrated into the beginning of a digital architecture: the material actualization of the field, therefore making visible its invisible forces. Armed with animation software, these architects will develop two opposing methodologies. A first one where soft bodies are deformed and animated by the multiplicity of forces ${ }^{3}$, and a second, where the vector field is evolving towards an architectural formation. ${ }^{4}$

In the latter approach, the generative process is prioritized in terms of architectural purpose, while the project per se is mainly defined by its local interconnectivity. As explained by Stan Allen in his seminal text "Field Conditions," the architect has to design a system capable of apprehending the perceptible, but often invisible, flow of the site in order to transform it into a physical and spatial element. ${ }^{5}$ Ali Rahim's "catalytic formations" concretize this explanation, while the architectural event literally emerges from the bottom-up, through active interactions in an open system, to generate towers, houses, shops, and other architectural entities. ${ }^{6}$ Such a design method obviously requires the architect to trust the evolving digital environment he has put in place, in his animation software. He then has to learn to master it, in order to see unpredictability and complexity appear in it. ${ }^{7}$ A double interdependency is then created between the generated object and the field. First, the object will be influenced by the field: "it is subject to the forces of the field; it is at some point part of the gradient by which the distribution of the field can be represented."8 Second, its own presence in the same field will then influence the degree of difference, since it: "intervenes in it as an active creator, by modifying the lines of force and the gradient distribution; one cannot define the gradient of a field without defining what is present at every possible point of it."9 In this way, the philosopher Gilbert Simondon demonstrates the importance of the dynamic and mutual associativity between the object and its energetic environment. This continuous interaction invalidates the notion of stability in the field, which would result from a linear relationship in the system, at the expense of the multiphasic notion of metastability, which results from a non-linear relationship. ${ }^{10}$ 


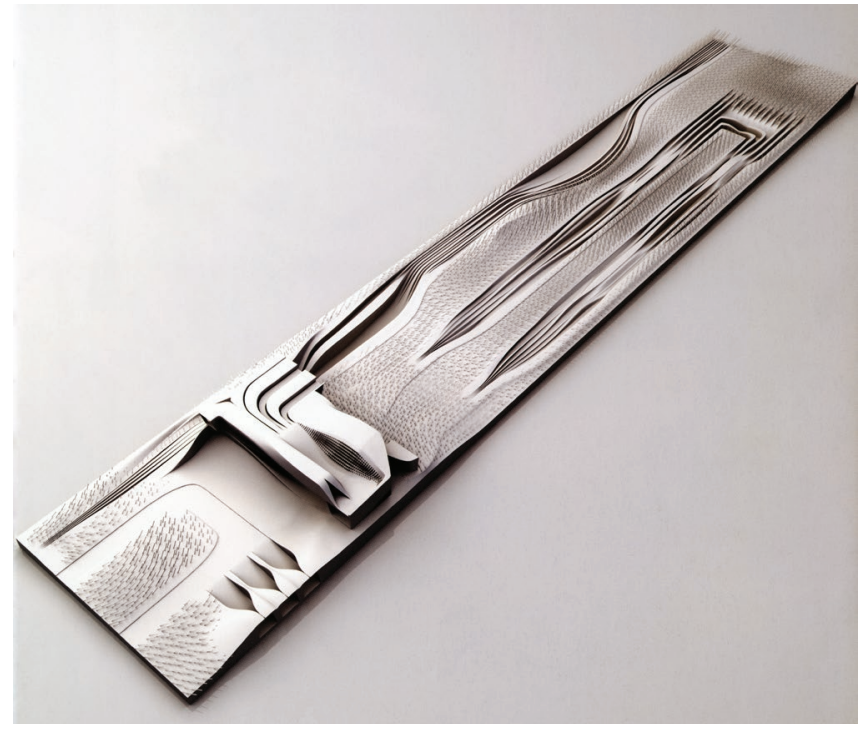

Figure 1. Residence for a fashion designer, C-A-P. (Reproduced by permission from Ali Rahim.)

Other groups of architects such as Kokkugia, Ruy Klein and Biothing will use systems of self-organizing agents ${ }^{11}$, fluid simulations and magnetic markers to produce material conditions in the field, bringing to the digital world the "disorder" of objective reality. ${ }^{12}$ An undeniable advantage emerges from these experiments. These generative processes, fed by their connections with their environment, will initiate the project at the most intense region in the field; at the peak where everything happens. ${ }^{13}$ Therefore, the resulting architectural project is not only a space in relation, but also a space of relation, as Simondon specifies where the boundary between the beginning of what constitutes the physical project and the end of the flow that initially formed it is getting blurry. ${ }^{14}$ These field projects seem to follow almost no proven architectural rules, no established paradigm, and we then realize that "the gap between what we know and what we believe we know is widening dangerously." ${ }^{15}$

\section{FIELD OF OBJECTS}

Several architects will want to materialize the globality of the field's information, to actualize its whole gradient rather than only bringing out the singularity. To this end, an initial component will be designed (a facade element, a spatial module, a diagrammatic form acting as a placeholder, etc.), following the definition of its neutral primitive stage, but capable of a reaction, or adaptation, according to the flow of information it receives. ${ }^{16}$ After that, the distribution of this component on a surface or in the architectural space will create a field of objects. According to their specific positioning in the field, each component/object will adapt, thus creating a set of continuous variations. ${ }^{17}$ This will have the negative consequence of drowning emergence and metastability, two essential elements for the fertility of the field, in a system with stable and predictable evolution. What is now called "parametric architecture," however, gives a high level of control to the designer, while the fundamental characteristics of the components, initially defined, are not altered in the development of the project. It is simply some aspect of it that will vary, by ratios or intervals, based on the intensity of the field. This approach will be so popular, both in academia and in practice, that Patrick Schumacher, now in charge of Zaha Hadid Architects, will decide to promote it as an architectural style; parametricism. ${ }^{18}$ The transformation of a modeling technique into a "conceptual recipe," including dogmas and taboos to be respected, will necessarily trivialize the results. ${ }^{19}$ This is particularly true in large-scale projects, such as ZHA's Kartal Pendik Masterplan, where the variable deformations of generic urban blocks offer visual satisfaction above all.

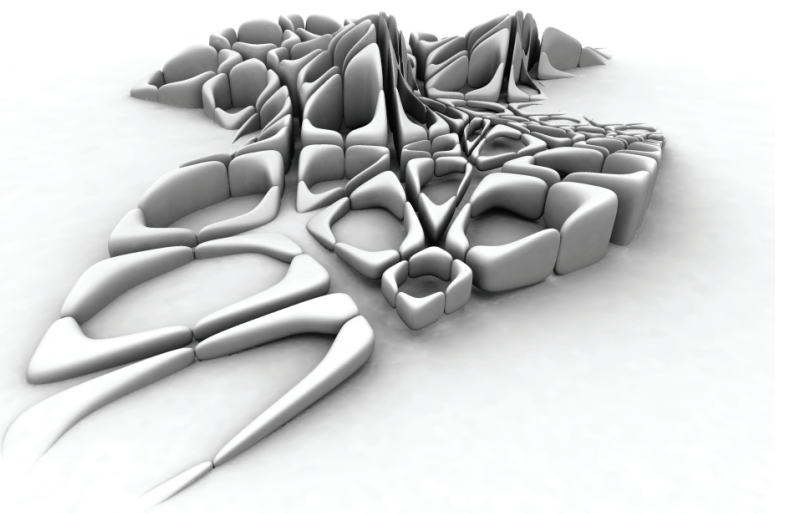

Figure 2. Kartal Pendik Masterplan, Zaha Hadid Architects. (Reproduced by permission from Zaha Hadid Architects.)

Many will criticize Schumacher's parametricism, following two important aspects. First, the use of a system of holistic networks can only be analyzed by its connections, since the possible outcomes are as numerous as the links that constitute it. As the philosopher Graham Harman points out: "the entities [of such a system] have no autonomous reality, but gain their reality from those other things with which they interrelate." ${ }^{20} \mathrm{As}$ if the object's properties would be "vaporized into an infinitely interconnected empire." ${ }^{21}$ It is therefore difficult to discuss mainly the qualities of the architectural object, since they are in fact a materialization of the information flow present in the network at that precise moment. Second, although the original intent of the field of objects was to integrate heterogeneity into the architectural design, the result is often the opposite. The unpredictability of the force field is reduced to an almost architectural homogeneity, while buildings are only one disconnection away from returning to their primitive stage has a component. This priority of relations over the object will even be identified by Mark Foster Gage as an evil paralyzing the discipline and architectural discourse. ${ }^{22} \mathrm{He}$ will then suggest a return to an architecture capable of being justified by its unique existence, and not by its relational dependencies. ${ }^{23}$ 


\section{OBJECT}

This ideological transition will be fed by the introduction of the object-oriented ontology (OOO, or Triple O) into architectural theory. ${ }^{24}$ This philosophy put forward the idea of a flat ontology of all objects, where hierarchies collapse to give an "ontological dignity to each individuated thing." 25 The main interest of $\mathrm{OOO}$ for architecture is the possibility of the "concrete entities again become a central philosophical problem." ${ }^{26}$ It is therefore a philosophy where objects can be approached "in themselves," ${ }^{27}$ at the center of a metaphysical scheme that requires from us, to admit that they do not exist only in relation to us. ${ }^{28}$ With that, all objects gain an existential autonomy, resulting in an inquiry about the relation they have with each other and with their context. Several architects will draw inspiration from it to refocus their research on the architectural object itself; now considered as an autonomous element, and the primary source of knowledge. ${ }^{29}$

As Michael Young points out: "In a blunt statement, as architects, we design objects. We may speculate on the events they will engender, we may test and evaluate their performative effects, we may hope for future relations and judge success on those terms, but in the moment of design, we create objects, and need to be able to treat them as such." ${ }^{130}$ So, what does it mean to design architecture as an object? It is not a question of creating meaningless forms or provoking the iconic, but rather shifting the focus from a generative process towards the object and its intrinsic qualities. ${ }^{31}$ Whether they are material, formal, spatial, or other, these specificities will mainly result from the design of the object itself, and so to speak, of the architect sensibility and design intuition. Several of Tom Wiscombe's projects illustrate this point, while he uses the strategy of nesting objects (enclosed living space housing the programmatic elements of the project) within a larger object (the building's outer shell). Wiscombe thus wishes to go beyond the digital surface by questioning the depth of architectural volumes. ${ }^{32} \mathrm{His}$ idea for the Guggenheim Helsinki is a good example. The tension created between the exhibition rooms and the main volume causes it to deform like a flexible membrane, adapting to internal forces. The main consequences will be, on the one hand, dissociation from the external environment by an egocentric conception, thus composing its own context. Second, the spatial qualities of the building, such as the interstitial atriums between the hidden objects, will result from the object itself, not from its external relations.

Consequently, the idea of autonomy becomes, once again, central to the design of the architectural object. Of course, the architect regains complete control over the project, by taking it out of the relational system of the field of objects. But beyond that, the object itself gains autonomy through its estrangement with the context. ${ }^{33}$ It becomes a kind of absolute architecture, as Pier Vittorio Aureli points out: "the term absolute is intended to stress, as much as possible, the individuality of the architectural form when this form is confronted with the environment in which it is conceived and constructed. I use absolute not in the conventional sense of "purity" but in its original meaning as something being resolutely itself after being "separated" from its other." ${ }^{34}$ Consequently, some architects, such as Young \& Ayata, will use the autonomous and self-referential object as a modus operandi. Their winning proposal for the new Bauhaus Museum begins with the design of an elementary vessel which will then be copied, moved and rotated on a grid, leading to a collective dialogue that forms a larger autonomous object, the museum. While from the outside there is a collection of vessels leaning against each other, the interior space results from the fusion of these objects. This creates a horizontal freedom for the plan, and causes a surprising series of vertical stretches, similar to deformed vaults, allowing zenithal light to penetrate the immaculate exhibition spaces.

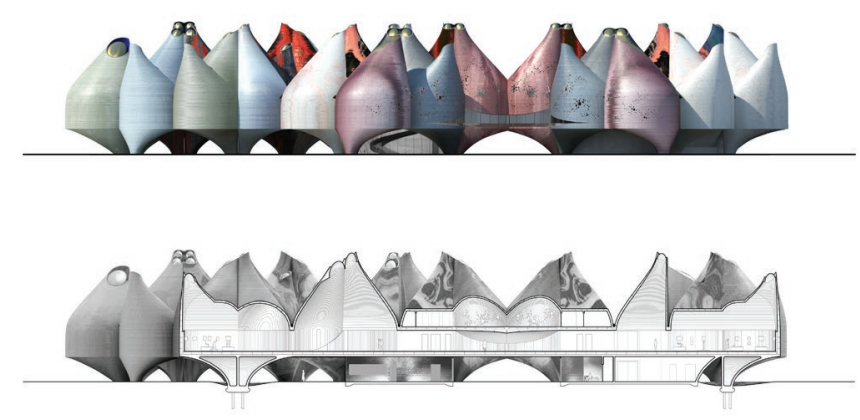

Figure 3. Vessel Collective - Bauhaus Museum, Young \& Ayata. (Reproduced by permission from Michael Young.)

It is important to understand that this autonomy by dissociation does not mean the complete isolation of the architecture; it is rather an affirmation of the uniqueness of the project and its distinctive qualities, thus returning to some fundamental and disciplinary issues. This separation establishes a contrast with certain elements of its environment, consequently developing relations through the distance with them, without, however, being reduced to it.

\section{OBJECT-FIELD}

Recently, several theorists and architects have tried to reconcile the autonomy of the architectural object with the unpredictability of the field. Rather than having the object emerge from the force field, or distributing objects in the field, this time they try to position the field within an object that already has a formal definition. It is through this method that architecture begins to act as an adaptive interplay between these 2 elements, allowing the emancipation of the conceptual intuitions of the architect, by giving form to the object, while still using later the deterministic power of digital processes such as the field. We will qualify the result an object-field. An interesting dialogue of simplexity is 
established between the beforehand designed object, often of simple form, and the field, generating a complex materiality in it. Therefore, the analysis of the object-field is relative to the scale at which it is observed. At the macro scale, the simple characteristics of the object will stand out, while at the meso scale, all the complexity of the field will be emancipated through its material expression. Finally, the micro scale will reveal almost simplistic elementary units, which will be called upon to evolve in the field, within the domain of the object. ${ }^{35}$ In this way, a symbiotic relationship can be established between the object and its constituent elements, as the philosopher Timothy Morton argues: "nothing exists all by itself, and so nothing is fully 'itself.'"'36

This important reasoning on the scale, or rather on the "resolution" of architecture, which results from this new junction between the object and the field, will be catalyzed by several factors including the technical improvement of high-precision 3d printers, capable of producing objects of unequalled finesse and of variable material properties. ${ }^{37}$ It is therefore possible to integrate the multi-scale hierarchy of matter into the design process, by programming it micron-by-micron, during the generation of the field within the objects. ${ }^{38}$ Following this logic, Roland Snooks' RMIT Mace project demonstrates the potential of "high resolution" design. ${ }^{39}$ Starting with the modeling of a hollow volume, Snooks will algorithmically deploy a population of agents seeking to develop emerging behavior. Through an iterative evolution, these digital agents will be transformed into a fibrous mass, by the materialization of their movements. In this way, the physical characteristics arise from within the object, but are not explicitly modeled. The result offers an alternative expression of the initial volume, through a bundle of finely intertwined curves. ${ }^{40}$ The direct interaction between the object and the field produces some fascinating effects: where fibrous compressions are observed on the surface of the volume and thus generating the grip of the object, or then at the ends where the agents start to act freely, while escaping the volume to express the unpredictable fluidity of the field..$^{41}$

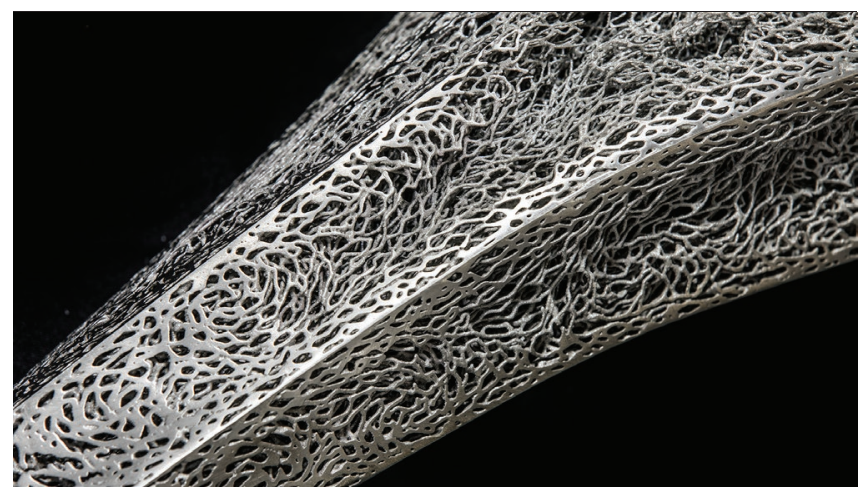

Figure 4. RMIT Mace, Roland Snooks and Scott Mayson (C) Kokkugia.
However, the use of $3 d$ printers clearly limits the size of the possible projects. In order to overcome this obstacle, a second approach to the object-field will involve by aggregation, combination and repetition of modular units. Rather than addressing the question at a granular level, this time the consideration begins at the meso scale, following a logic of discretizations. Gilles Retsin will propose a series of projects where the complex assembly of a single module will produce the entire architectural gesture. These Stick Projects, as the architect calls them: "start to dissolve defined wholes, introducing a porous assembly based on parts. This kind of approach relates more to Stan Allan's field conditions [...] (which) are based on serial repetition, and the dissolution of the figure." 42

The generative process of projects such as KarlsPlatz, Blockhut and Suncheon Art Platform, is based on the voxelization of a defined architectural space, within which a vector field act. ${ }^{43}$ Each voxel, acting as a placeholder, will evaluate the field according to its position, then use the vector data to guide the positioning of a discrete element. This iterative loop will repeat until all the voxels are replaced by these material modules, thus generating an architecture of messy discreteness, as articulated by Mario Carpo: "in its pristine, raw state - without the mediation or the shortcut of elegant, streamlined mathematical notations." ${ }^{44}$ Retsin's object-field embodies a second degree of materialization of the system, whereas the field is primarily used to determine the arrangement of discrete elements within a modeled object. It is therefore possible to argue that these elementary units and the whole object are both autonomous and interrelated, which the philosopher Levi Bryant will describe as a "strange mereology." 45

To understand why this mereology is such a strange mereology, we must recall that all objects are independent or autonomous from one another. Objects can enter into exo-relations with one another, but they are not constituted by their relations. Put differently, their being does not consist of their relations. Consequently, the strangeness of this mereology lies in the fact that the subsets of a set, the smaller objects composing larger objects, are simultaneously necessary conditions for that larger object while being independent of that object. Likewise, the larger object composed of these smaller objects is itself independent of these smaller objects. ${ }^{46}$

However, the coherence of the whole can only be developed through the logical layout of the modules. As a result, architects such as Jose Sanchez, Daniel Köhler and Casey Rehm, will develop different methods based on the modular combination to design architectural structures. Sanchez's Polyomino projects are particularly significant, as each unit has a number of connectors, positioned on different faces or edges, allowing a series of combinations, while making 


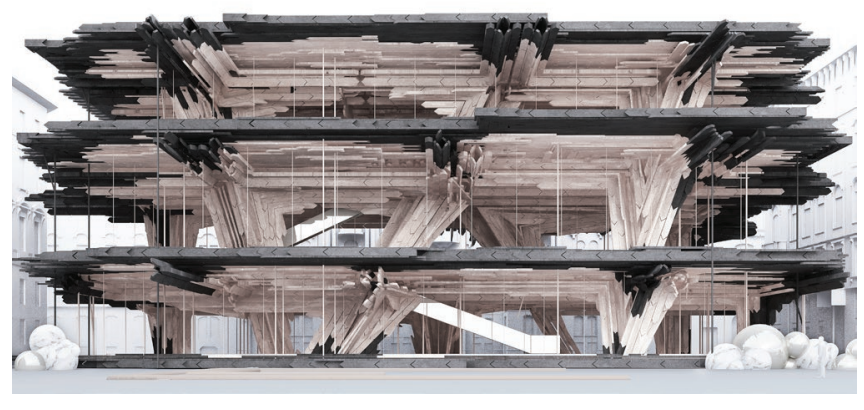

Figure 5. KarlsPlatz, Gilles Retsin. (Reproduced by permission from Gilles Retsin.)

other impossible. ${ }^{47}$ This three-dimensional puzzle shapes the object-field through discrete aggregation, guided by a process that combines algorithmic iteration and the designer intuition..$^{48}$ The final qualities of the object-field will emerge from this assembly, where the expression of a new syntax allows the modules to be moved continuously while maintaining their autonomy.

\section{CONCLUSION}

In conclusion, an in-depth architectural thinking based on the field, the object and their interactions, offers several answers to the question initially raised, regarding the notion of control in digital design, through the continuous interaction between the deductive and the inductive. As demonstrated by the experiments in the era of the field, the emergence linked to generative processes should therefore not be seen as an element that calls into question the role of the designer, but rather as a conceptual method to be exploited and then integrated into rigorous architectural process. The field of objects leading to the parametric compositions may have seemed, at first glance, capable of channeling the raw energy of the field, but the large-scale results seemed rather to dilute it through semi-differentiated repetitions. The object, on the other hand, has made it possible to bring back to the table certain fundamental questions about the architectural discipline, mainly around the autonomy of the form and the ability of architecture be justified by itself, while somehow overlooking the lessons learned from the field, a few years earlier. Finally, this brief review of recent history has led us to create the adaptive interplay that is the object-field by extrapolating the potential of the object, without totally isolating it, by integrating the contingent qualities of the field into its materialization. In this way, it allows us to consolidate the achievements of the digital period, while widening the theoretical, conceptual and technical dialogue with other areas of knowledge, whether scientific or philosophical. Finally, by unifying the aspects of autonomy and unpredictability, the object-field clearly expresses the importance of the architect's intuition, as well as the need for digital tools and fabrication machines, in the pursuit of architectural novelty.

\section{ENDNOTES}

1 Although the term "cybernetics" was officially introduced in 1948 with the publication of Norbert Wiener's Cybernetics: Or Control and Communication in the Animal and the Machine (Cambridge, MA: The MIT Press, 1948), the idea of cybernetics was developed in the 1940s, through military research and then in the theoretical realm with the famous Macy conferences from 1946 onwards. See Mathieu Triclot, Le moment cybernétique, la constitution de la notion d'information (Paris: Édition Champ Vallon, 2008).

2 Arnaud Macé, La matière (Paris: Flammarion, 1998), 84. Translation by authors.

3 Greg Lynn, Animated Form (New York: Princeton Architectural Press, 1999).

4 Ali Rahim, Catalytic Formations; Architecture and Digital Design (New York: Taylor \& Francis, 2006).

5 Stan Allen, "Field Conditions (1997)" in The Digital Turn in Architecture 1992 2002, ed., Mario Carpo (London: Wiley, Architectural Design, 2015), 62-79.

6 See the projects of C-A-P (Contemporary Architectural Practice) by Ali Rahim and Hina Jamelle.

7 Allen, "Field Conditions (1997)."

8 Gilbert Simondon, L'individu à la lumière des notions de forme et d'information (Grenoble, France: Jérôme Million, 2005), 538-539. Translation by authors.

9 Gilbert Simondon, L'individu à la lumière des notions de forme et d'information. Translation by authors.

10 Gilbert Simondon, L'individu et sa genèse physico-biologique (Paris: Presses Universitaires de France, 1964), 75.

11 Agents are digital particles that follow simple rules to move around (e.g., moving in one specific direction, keeping a certain distance from your neighbors, etc.). When simulating a population of agents, it is possible to create emerging behaviors, similar to flock of birds or schools of fish.

12 Lorraine Daston and Peter Galison, Objectivity (New York: Zone Books, 2007).

13 Gilles Deleuze and Félix Guattari, Mille plateaux, capitalisme et schizophrénie 2 (Paris: Édition de minuit, 1980), 458.

14 Simondon, L'individu à la lumière des notions de forme et d'information, 328.

15 Nassim Nicholas Taleb, Le Cygne Noir ; La puissance de l'imprévisibilité (Paris: Les belles lettres, 2012), 20. Translation by authors.

16 Rivka Oxman and Robert Oxman, eds., Theories of the Digital in Architecture (New York: Routledge, 2014).

17 Michael Hensel and Achim Menges, eds., Morpho-ecologies (London: Architectural Association Publishers, 2006).

18 Patrik Schumacher, The Autopoiesis of Architecture, A New Framework for Architecture Volume 1 (London: Wiley, 2011).

19 Negative heuristics (taboos): avoid rigid geometry, simple repetitions, juxtaposition of unrelated elements or systems.

20 Positive heuristics (dogmas): all forms parametrically malleable, differentiate gradually (at varying rates), inflect and correlate systematically.

21 See Patrik Schumacher "Parametricism: A New Global Style for Architecture and Urban Design" AD Architectural Design-Digital Cities 79, no. 4 (July/ August 2009): 16.

22 Graham Harman, "Objets et Architecture, Objects and Architecture" in Naturaliser I'architecture naturalizing, Catalogue Archilab, Marie-Ange Brayer and Frédéric Migayrou, eds. (Orléans: Éditions HYX, 2013), 235.

23 Graham Harman, "Object Oriented Philosophy" in Towards Speculative Realism, Essays and Lectures (Winchester: Zero Books, 2010), 102.

24 Foster Gage will not be the only one to make this observation. Eric Owen Moss will make many interventions on this issue during, among other things, his participation in the symposium on architecture and beauty (Sci-Arc, 2011) and during a debate on the fundamental elements of architecture and autopoiesis (AA, 2011) organized by Schumacher.

25 Mark Foster Gage, "Killing Simplicity: Object- Oriented Philosophy in Architecture" Log 33 (Winter 2015): 104.

26 It is worth noting that David Ruy (RuyKlein) will be one of the first, if not the first, to import 000 ideas into the architectural sphere.

27 Tristan Garcia, Forme et objet; un traité des choses (Paris: Presses Universitaires de France, collection Métaphysiques, 2010), 11; Tristan Garcia, Form and Object; A Treatise on Things, trans., Mark Allan Ohm and Jon Cogburn (Edinburg: Edinburg University Press, 2014), 4.

28 Graham Harman, Tool-Being, Heidegger and the Metaphysics of Objects (Chicago: Open Court, 2002), 49.

29 Quentin Meillassoux, Après la finitude (Paris: Éditions du Seuil, 2006), 18-19. Translation by authors.

30 Ian Bogost, Alien Phenomenology or What It's Like to Be a Thing (Minneapolis: University of Minnesota Press, 2012), 14. 
31 Michael Young, The Estranged Object (Chicago: Graham Foundation, 2015), 6.

32 Young, 30.

33 Gilles Retsin "Something Else, Something Raw" Architectural Design 86, no. 6 (November/December 2016): 85.

34 Tom Wiscombe "Discreteness, or Towards a Flat Ontology of Architecture," Project, A Journal for Architecture 3 (2014): 4-43.

35 The notion of autonomy has been at the center of several architectural discourses in history; initially introduced by Emil Kaufmann in his explanation of the liberation of architects from the classical order, opting for a freer and more flexible approach in the composition of volumes. See Emil Kaufmann, De Ledoux à Le Corbusier. Origine et développement de l'architecture autonome (Paris: Édition la Villette, 2015).

36 Pier Vittorio Aureli, The Possibility of an Absolute Architecture (Cambridge, MA: The MIT Press, 2011), ix.

37 Jeffrey Kluger, Simplexity (New York: Hyperion, 2008).

38 Timothy Morton, The Ecological Thought (Cambridge, MA: Harvard University Press, 2010), 15.

39 The accuracy of industrial 3D printers can be as high as +/- 15 microns.

40 Bob Sheil, “High Definition: Zero Tolerance” Architectural Design 84, no. 1 (January/February 2014).

41 In collaboration with the designer Scott Mayson.

42 Roland Snooks, "Affects of Intricate Mass" in Evoking Through Design: Contemporary Moods in Architecture (Hoboken, NJ: Wiley, 2017), 72-77.

43 Snooks will use this methodology in the generation of many projects (such as the NGV Pavilion, Babiy Yar Memorial and the National Art Museum of China), as well as in his extensive research on composite materials (Composite Wings, Composite Skeleton and Composite Swarm).

44 Gilles Retsin, "Discrete and Digital" in TxA Emerging Design + Technology Proceedings (Austin, TX: Texas Society of Architects, 2016).

45 This field can express the distribution of loads in the volume or simply vector directions following attraction or repulsion points, or other guiding elements.

46 Mario Carpo, The Second Digital Turn; Design Beyond Intelligence (Cambridge, MA: The MIT Press, 2017), 70.

47 The concept of mereology deals with the relation between the parts and the whole.

48 Levi Bryant, The Democracy of Objects (Ann Arbor: Open Humanities Press, 2011), 214.

49 "Plethora-Project" official website. https://www.plethora-project. com/polyomino-1/.

50 Jose Sanchez, "Combinatorial Design; Non-Parametric Computational Design Strategies" in ACADIA 2016 Posthuman Frontiers: Data, Designers, and Cognitive Machines - Proceedings of the 36th Annual Conference of the Association for Computer Aided Design in Architecture, eds., Kathie Velikov, Sean Ahlquist, and Matias Del Campo (Fargo, ND: ACADIA, 2016), 44-53. 